\title{
Investigation of the Degree of Perceived Face Threat in Low, Medium, and High face threat situations regarding Politeness theory in Iranian EFL Contexts
}

\author{
Ali Faridizad, Shahla Simin \\ English Department, Najafabad Branch, Islamic Azad University, Najafabad, Iran \\ E-mail address: afaridizad26@gmail.com; shahlasimin@yahoo.com
}

\begin{abstract}
Keywords: Perceived face threat; Perceived face threat scenarios; Politeness theory
\end{abstract}
\begin{abstract}
The goal of this study was to investigate the degree of perceived face threat in three different situations namely low, medium, and high face threat situations with respect to politeness theory in Iranian EFL Contexts. To obtain this purpose, 140 undergraduate students including 70 males and 70 females majoring in English literature, translation and teaching from Sheik-Bahai University were selected. This sample was chosen by means of stratified random sampling procedure. A questionnaire was utilized as the instrument to examine the degree of perceived face threat in three aforementioned situations. The data gathered by means of the questionnaire were analyzed to find out the answer to the research question. In general, the findings revealed that there was a statistically significant difference among students' performance in perceived face threat scenarios.
\end{abstract}

\section{INTRODUCTION}

Scholars have long given perceived face threats a central role in variables such as outcomes, relationships, interpersonal settings, and business settings. A face threatening act is the denial of one's self-image, attributes, accomplishments, and autonomy (McCroskey \& Richmond, 1975; Cupach \& Carson, 2002). The perceived face threats have been studied in terms of different variables. Some studies have examined the concept of perceived face threat across cultures (Ho, 1976; Cardon \& Scott, 2003; Yabuuchi, 2004; Liu, 2002). For example, Liu (2002) observed that face saving was a big concern for Chinese students in U.S. classes and concluded that realizing the differences will decline the degree of perceived face threats in cross-cultural contexts.

Other studies have addressed the effect of perceived face threats on outcomes and relationships (Carson \& Cupach, 2000; Park \& Guan, 2006; Cupach \& Carson, 2002). For instance, in a study performed by Cupach and Carson (2002), it was observed that a high level of face threat is associated with a high level of negative emotional outcomes. They also found perceived face threats would damage the relationships. The influence of perceived face threat has also been studied in a variety of contexts such as interpersonal settings (Cupach \& Carson, 2002; Cai \& Han, 2005; Park \& Guan, 2006), and business settings (White, Tynan, Galinsky, \& Thompson, 2004; Carson \& Cupach, 2000).

However, it seems that educational contexts such as classrooms have not received adequate attention with regard to perceived face threat.

\section{LITERATURE REVIEW}

Instructors' characteristics such as age, degree, and behavior are of paramount importance regarding perceived face threats. There is evidence that the instructor contributes to students' levels of participation, and students believe that their professors influence their participation based on the ways in which the professors communicate with them (Fritschner, 2000).

Karp and Yoels (1976) found that "the actions of the teacher are indeed most crucial in promoting classroom interaction" (p. 426). Wade (1994) noted that a primary reason students do not participate may be because of the instructor. Specifically, students are less likely to participate if 
their professors do not pay attention to them, make fun of them, put them down, or are overly critical of them.

Similarly, Kearney, Plax, Hays, and Ivey (1991) found that offensive behaviors engaged in by instructors, including using sarcasm and putdowns, being verbally abusive toward students, sexually harassing students, and having a negative personality had a negative impact on the classroom and students' participation. Berdine (1986) found that instructors who were considered "boring, bored, pushy, moody, close-minded, too opinionated, condescending, and unfriendly" (p. 23) were likely to be faced with students who do not participate in class.

Supportive climates can be created by knowing students' names (Fritschner, 2000; Nunn, 1996), even if it is only a few names in a large class and by giving students written or oral encouragement and praise (Phoenix, 1987). Hyde and Ruth (2002) also found that students were more likely to participate if they considered the climate to be supportive, and noted that the professor should work to create this type of environment by providing positive feedback and handling controversial topics with grace.

Fassinger (2000) surveyed both students and professors and found that higher participation classes were more supportive, cooperative, and student-centered, had students who were less concerned about what others thought and interested in their classmates' opinions, and had professors who were approachable and knew their students' names.

Alternatively, a climate where students and the instructor respect each other, where the students respect one another, and where the instructor cares about the students, is conducive to class participation (Crombie et al., 2003), as it is this type of classroom climate that works to increase students' confidence and comfort in participation. Mottet, Martin, and Myers (2004) found that students were more motivated to speak up in class if they perceived their instructors as inclusive and appreciative of them and as using verbal approach strategies. They were also more likely to participate if they perceived their instructors as physically or socially attractive (Myers et al., 2009).

Clearly, the instructor plays a critical role in the degree of perceived face threats, depending on whether he/she creates a supportive climate for the students through appreciation, effective feedback, respect and caring, admiration of students; learning and grade, and so on.

The significance of this study is worth noting. The results of this study may contribute to improving the relevant theories.

\section{METHODOLOGY OF THE STUDY}

\subsection{Participants}

Participants for this study included undergraduate students majoring in English literature, English translation, and English language teaching in Sheikh Bahaei University, Isfahan, Iran. The participants selected for the present study included 140 students. The participants 'age was between 18 and 26 and they were from different regions of Iran. Participants were divided in two groups of male and female. Each group consisted of 70 students. This sample was chosen from the accessible population mentioned above by means of stratified random sampling procedure. Hence, all the members in the population of the study had an equal chance of being selected for the sample.

\subsection{Instruments}

The chief instrument of the study is a questionnaire utilized to investigate the degree of perceived face threat in high, medium, and low situations.

\subsection{Data collection}

The survey method was used for this study to investigate the degree of perceived face threat in three different situations.

\subsection{Data analysis}

The current study employed a version of the survey instrument that included only quantitative items. Thus, the survey exclusively contained closed-ended questions. The items were 
grouped into scales. The scales specifically examined variables addressed in the study. The data accumulated by means of the questionnaire were analyzed to determine the answer to the research question. In so doing, the software, Statistical Packages for the Social Sciences (SPSS), was run.

\section{RESULTS}

As it was mentioned earlier in the study, the purpose of this study was to investigate the degree of perceived face threat in high, medium, and low situations. The study was guided by a research question. The following tables and figure indicate the descriptive and inferential statistics of results.

\subsection{Answering the research Question}

The research question of the study mentioned below will be answered. The results also would be yielded in details.

RQ: Is there any significant difference in the degree of perceived face threat for participants who experience low, medium, and high face threat situations?

H: There is no significant difference in the degree of perceived face threat for participants who experience low, medium, and high face threat situations.

To answer the research question a one-way analysis of variance (ANOVA) was adopted. The division of the factor variable, scenario, was in three levels, namely 1 (= high face threat situation), 2(= medium face threat situation), and 3(= low face threat situation). Table 4.1 shows the results of ANOVA.

Table 4-1

Results of ANOVA for PFT scenarios

\begin{tabular}{l|c|c|c|c|c}
\hline PFT & Sum of Squares & df & Mean Square & F & Sig. \\
\hline Between Groups & 507.406 & 2 & 253.703 & 7.911 & $\mathbf{. 0 0 0}$ \\
Within Groups & 8273.797 & 258 & 32.069 & & \\
Total & 8781.203 & 260 & & & \\
\hline
\end{tabular}

$\mathbf{P}<.05$

As can be seen, there was a statistically significant difference among students' performance in PFT scenarios with respect to $\mathrm{F}=7.911$ at $\mathrm{P}<.05$. Therefore, the null hypothesis failed to be supported. However, the current table does not indicate on which scenario(s) the difference lies. To investigate the difference, Post-Hoc LSD Multiple Comparison was conducted. Table 4.2 presents the results.

Table 4-2

Results of LSD test on PFT at different scenarios

\begin{tabular}{|c|c|c|c|c|c|}
\hline \multirow[b]{2}{*}{ PFT } & \multirow{2}{*}{$\begin{array}{c}\text { Mean Difference } \\
(\mathrm{I}-\mathrm{J})\end{array}$} & \multirow[b]{2}{*}{ Std. Error } & \multirow[b]{2}{*}{ Sig. } & \multicolumn{2}{|c|}{$95 \%$ Confidence Interval } \\
\hline & & & & Lower Bound & Upper Bound \\
\hline scenario 1 scenario 2 & $3.120^{*}$ & .801 & .000 & 1.54 & 4.70 \\
\hline scenario 3 & $2.225^{*}$ & .920 & .016 & .41 & 4.04 \\
\hline scenario 2 & $-3.120^{*}$ & .801 & .000 & -4.70 & -1.54 \\
\hline scenario 3 & -.895 & .920 & .332 & -2.71 & .92 \\
\hline scenario 3 & $-2.225^{*}$ & .920 & .016 & -4.04 & -.41 \\
\hline scenario 2 & .895 & .920 & .332 & -.92 & 2.71 \\
\hline
\end{tabular}

*. The mean difference is significant at the 0.05 level. 
The post-hoc multiple comparison revealed that scenario 1 is significantly different from scenario 2 and scenario 3. However, no significant difference was observed between scenario 2 and scenario 3. A better understanding of the findings can be drawn upon the following figure.

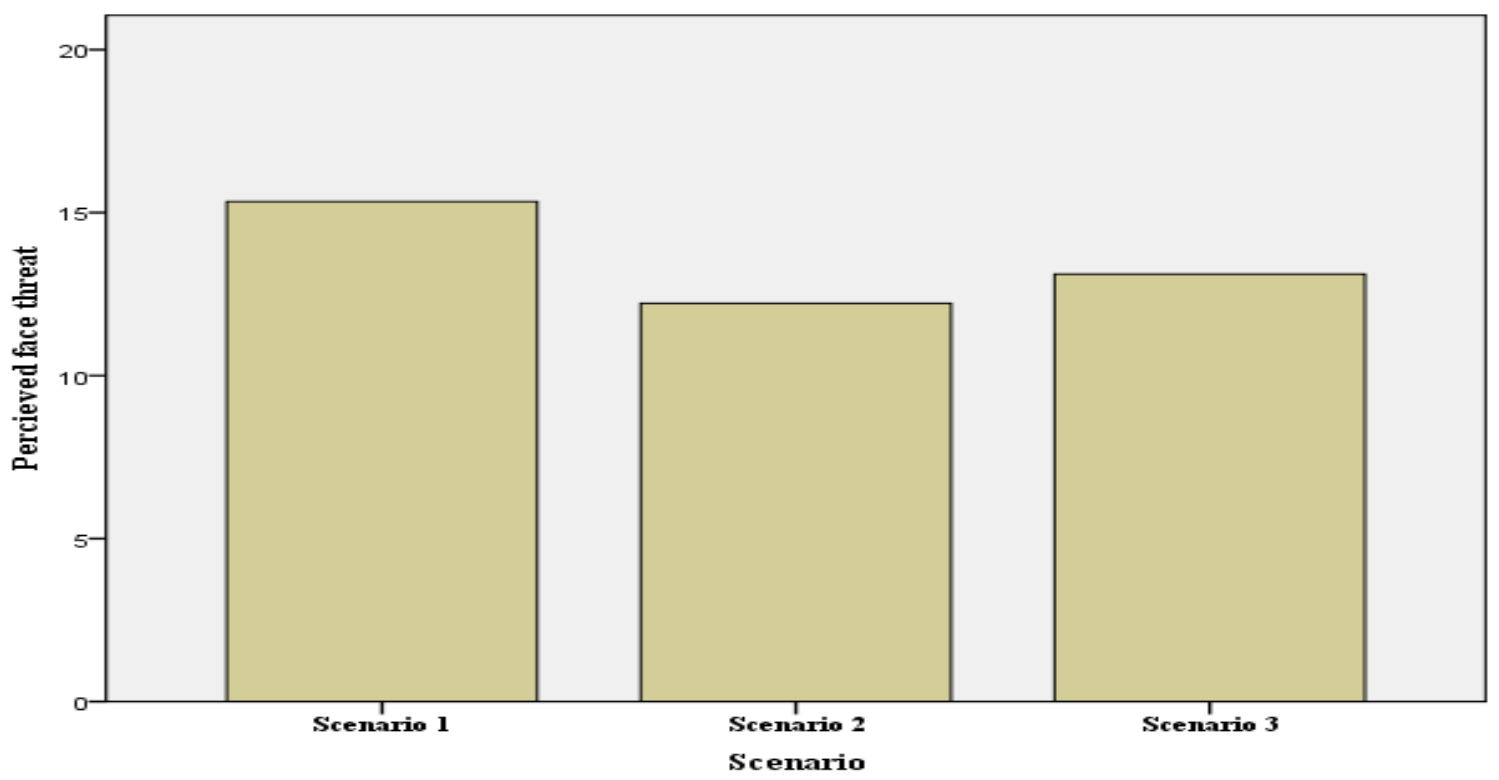

Figure 4-1: Mean score of perceived face threat at different scenarios

Figure 4.1 demonstrates mean score of perceived face threat at different scenarios. As can be seen, the mean score of the students' performance in the first scenario (high face threat situation) is the highest.

\section{DISCUSSION AND CONCLUSION}

The research question sought to find any significant difference in the degree of perceived face threat for participants who experience low, medium, and high face threat situations. Having analyzed the data via ANOVA, the researcher found significant differences in student's performance in PFT scenarios. The mean score of the students' performance in the first scenario (high face threat situation) was the highest. Accordingly, it can be concluded that the college instructor's characteristics stated in the questionnaire (age, degree, and intimacy) influenced students' perceptions of face threat. In other words, asking a question in a class where the instructor is a full professor who is over sixty years old appears more difficult and challenging than a class wherein the instructor is either a middle-aged assistant professor (scenario 2) or a young teaching assistant (scenario 3). The findings are partially consistent with those of Zheng (2008). It is stated partially because in her cross-cultural study among Chinese and American students, Zheng found significant differences only among Americans. Thus, the findings of this study can support the idea that Iranians' performance in high PFT situations is congruent with that of Americans.

\subsection{Implications}

Planning upon the major findings of the study concerning learners' degree of PFT, teachers should make hard efforts to create non-face threatening situations. The current study employed teacher's features and behavior, i.e. age, degree, and intimacy of the relationship as the basis to examine students' perceptions of face threat. Then, upon the outcomes of this instrument some suggestions can be offered to create non-face threatening classrooms. For instance, teachers should be encouraged to increase face-to-face interactions with students out of the class. Moreover, teachers' availability and responsiveness should be cajoled. 


\section{References}

[1] Berdine (1986) "Why Some Students Fail to Participate in Class." Marketing News, Volume Twenty, Number Fifteen, 23-24. Brown, C.

[2] Fassinger, P. A. (1995). Understanding classroom interaction. The Journal of Higher Education, 66, 82-96.

[3] Fritschner, L. M. (2000). Inside the undergraduate college classroom: Faculty and students differ on the meaning of student participation. The Journal of Higher Education, 71, 342-362.

[4] Hyde, C. A., \& Ruth, B.J. (2002). Multicultural content and class participation: Do students self-disclose? Journal of Social Work Education, 38, 241-256.

[5] Karp, D. A., \& Yoels, W. C. (1976). The college classroom : some observations on the meanings of student participation. Sociology and Social Research, 60, 421-439.

[6] Kearney, P., Plax, T. G.,Hays, E. R., \& Ivey, M. J. (1991). College teacher misbehaviors: What students don't like about what teachers say and do. Communication Quarterly, 39, 309324.

[7] Wade, R. (1994). Teacher education students'views on classroom discussion: Implications for fostering critical reflection. Teaching and teacher education, 10, 231-243.

[8] Phoenix, C. Y. (1987). Get them involved! Styles of high-and low-rated teachers. College Teaching, 35, 13-15. 